\title{
Osteosarcoma of Mandible
}

\author{
${ }^{1}$ Shikha Satish Bhatt, ${ }^{2}$ Shilpa Patel, ${ }^{3}$ Jigna Pathak, ${ }^{4}$ Niharika Swain
}

\begin{abstract}
Osteosarcomas (OS) are malignant neoplasms of the bone that commonly affect the long bones with rare presentation in jaws. Osteosarcomas of jaws represent about 6 to $8 \%$ of all OS, with an incidence of approximately 1 in 1.5 million persons per year. Although the exact cause of OS is still unknown, defects in the retinoblastoma $(\mathrm{RB})$ and $\mathrm{p} 53$ genes play an important role in the process. It is characterized histologically by anaplastic stroma with direct osteoid production. Here, we report a case of OS in a 30 -year-old female, who came with a massive bony swelling in the right mandibular region.
\end{abstract}

Keywords: Osteoblastic variant, Osteosarcoma, Sunburst appearance.

How to cite this article: Bhatt SS, Patel S, Pathak J, Swain N. Osteosarcoma of Mandible. J Contemp Dent 2016;6(1):70-74.

Source of support: Nil

Conflict of interest: None

\section{INTRODUCTION}

The term "osteosarcoma", also known as osteogenic sarcoma (OS), refers to a heterogeneous group of primary malignant neoplasms affecting bone forming or mesenchymal tissue that is characterized by formation of osteoid tissue. ${ }^{1}$ It occurs most commonly in long bones of extremities near metaphyseal growth plate. Osteogenic sarcoma of jaw is rare and represents only 6 to $8 \%$ of all OS. Jaw OS usually presents themselves in the $3 \mathrm{rd}$ and 4 th decades of life, almost a decade after their presentation in long bone tumors with a slight predilection for the mandible. ${ }^{2}$ The exact etiology is unknown. Three main factors generally may play an important role in their development-irradiation, preexisting benign bone disorders, and genetic predisposition. Biologically, OS of the jaw is considered to be less aggressive with a lower incidence of metastasis and hence better prognosis than that occurring in long bones. ${ }^{3}$ Despite modern treatment protocols that combine chemotherapy, surgery, and sometimes radiotherapy, the 5-year survival rate for

\footnotetext{
${ }^{1}$ Postgraduate Student, ${ }^{2}$ Professor and Head, ${ }^{3}$ Professor ${ }^{4}$ Lecturer

${ }^{1-4}$ Department of Oral Pathology and Microbiology, MGM Dental College and Hospital, Navi Mumbai, Maharashtra, India
}

Corresponding Author: Shikha Satish Bhatt, Postgraduate Student, Department of Oral Pathology and Microbiology, MGM Dental College and Hospital, Navi Mumbai-410209, Maharashtra India, Phone: +9127436604, e-mail: shikh-abhatt24@gmail.com patients diagnosed with OS remains at 50 to $70 \%{ }^{4,5}$ Here, we report a case of a 30-year-old female with mandibular bony swelling diagnosed as OS.

\section{CASE REPORT}

A 30-year-old female reported to Department of Oral Pathology and Microbiology, MGM Dental College and Hospital, Navi Mumbai, with a chief complain of swelling in lower right back region since 8 months. Patient was asymptomatic 8 months ago but started experiencing a swelling with respect to lower right half of the face. Swelling was small initially. Patient visited a local dentist who extracted a tooth from lower right back region. Swelling had gradually increased to its present size. No history of trauma was noted. There was no history of any other disease affecting the jaw or other bones. Medical and family history were noncontributory.

On extraoral examination, a diffuse swelling was present on the right side of face, extending from the zygoma inferiorly 2 to $3 \mathrm{~cm}$ below the chin. Anteriorly, it extended from just beyond the midline (left side) to the right preauricular region (Fig. 1). Anteroposteriorly, it measured about $12 \times 9 \mathrm{~cm}$ in size. Overlying skin was normal but tensed and not associated with any sinus or fistula. Borders of the swelling were poorly demarcated (Fig. 2). There was no evidence of extraoral draining sinus. Temperature of the overlying skin was normal. An intraoral examination revealed an ill-defined, diffuse, ulceroproliferative lesion showing bicortical expansion obliterating the buccal and lingual vestibular spaces on the right side of the mandible. The soft tissue growth showed indentations of the maxillary teeth. Mucosa over the swelling was inflamed (Fig. 3). Floor of the mouth was raised on the right side. On palpation, the swelling was tender and hard to firm in consistency. Grade II mobility was seen in all teeth from 33 to 47 . Orthopantomograph (OPG) showed a diffuse radiopacity with a sunburst appearance on right side of the mandible extending from 45 to 48 region (Fig. 4). Periodontal widening of the lower anterior teeth along with two root pieces and two missing teeth was seen. Computed tomography (CT) scan showed bone forming malignant mass of $8 \times 4 \mathrm{~cm}$ approximately arising from right hemimandible with sunburst periosteal reaction and not breaking the lingual border of the mandible. Externally, it extended up to subcutaneous tissue. Superiorly, the lesion extended up to the level of maxillary alveolus and inferiorly up to submandibular 


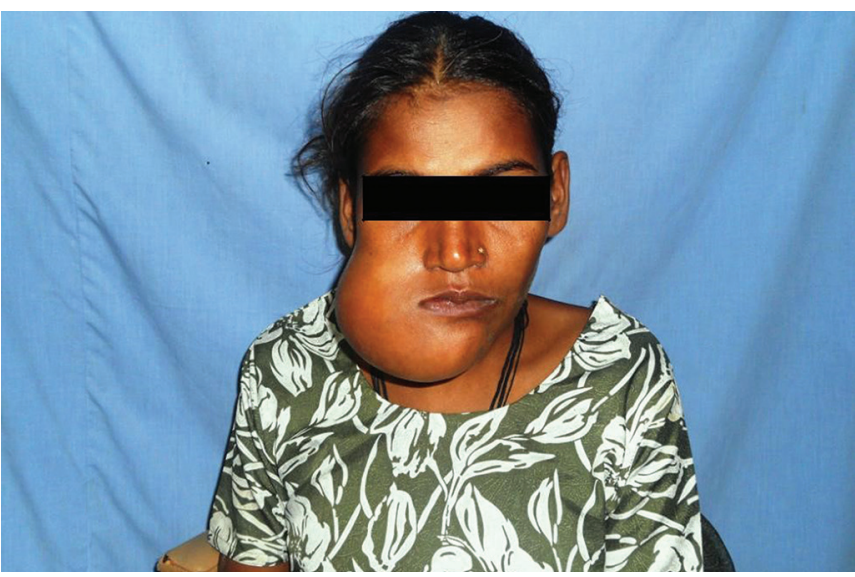

Fig. 1: Extraoral view shows a diffused swelling present on right side of face with no surface ulceration

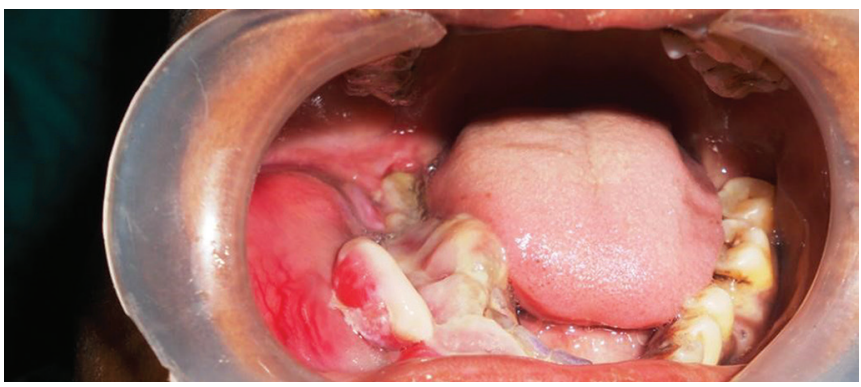

Fig. 3: Intraoral view shows an ill defined, diffused ulceroproliferative lesion showing indentation of maxillary posteriors, bicortical expansion obliterating the buccal and lingual vestibular spaces

soft tissue (Fig. 5). Three-dimensional (3D) reconstruction image confirmed the extent of the lesion (Figs 6A and B).

Considering the clinical features, the sudden increase in size of the swelling, consistency of the lesion, and the

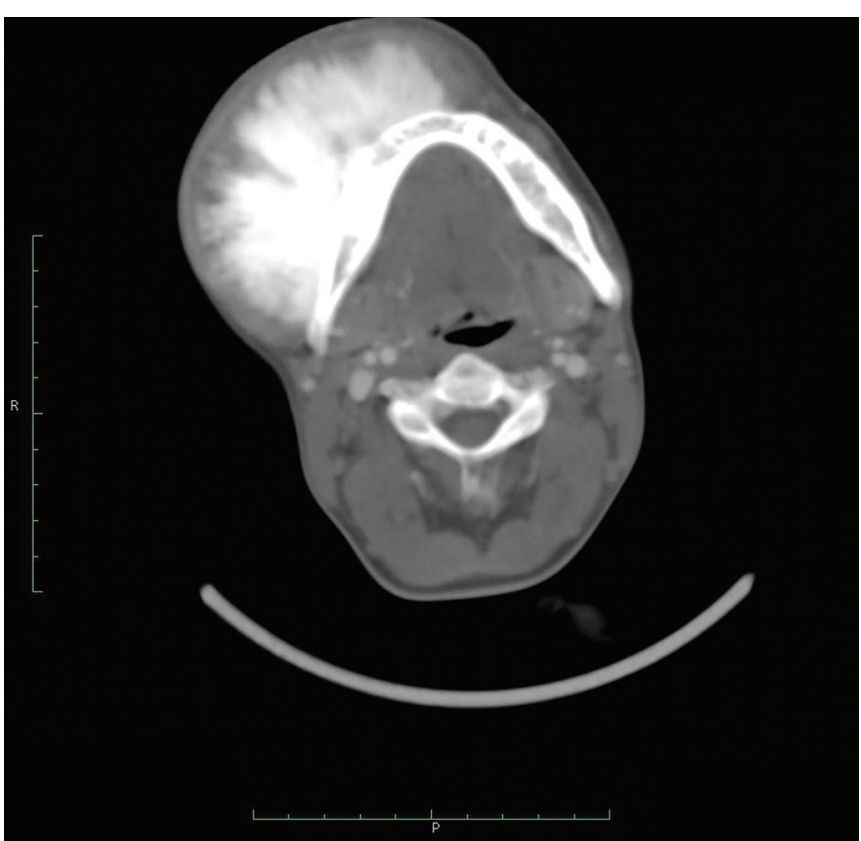

Fig. 5: Computed tomography scan shows bone forming malignant mass arising from right hemimandible with sunburst periosteal reaction

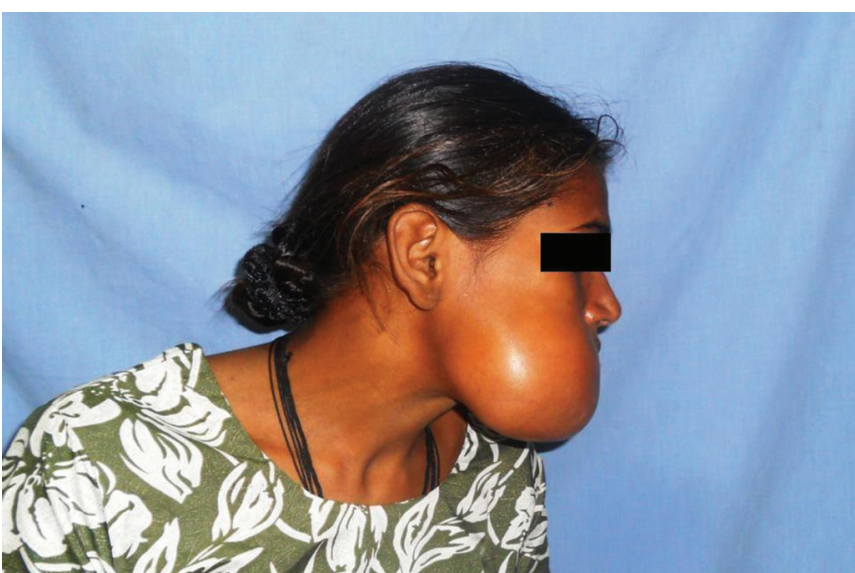

Fig. 2: Extraoral view shows swelling extending from zygoma to 2 to $3 \mathrm{~cm}$ below the chin. Anteriorly it extends from just beyond the midline (left side) to right preauricular region

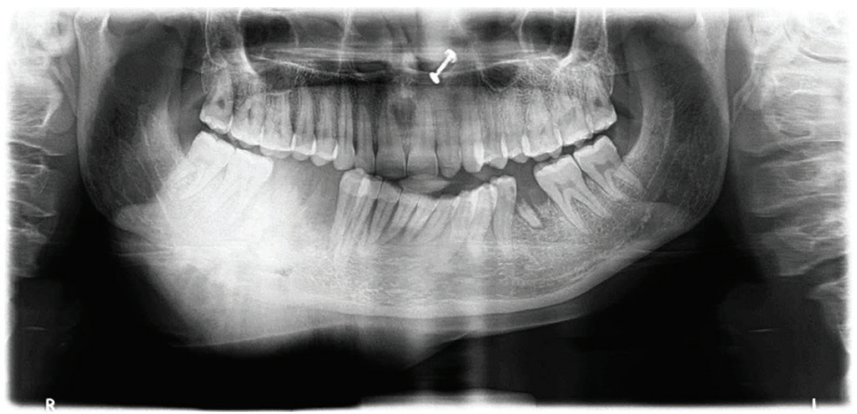

Fig. 4: Orthopantomography view shows diffuse area of increased radiopacity in relation to right side of the mandible having radiating appearance at the periphery (sunburst appearance)

patient's age, a provisional diagnosis of OS, fibrosarcoma, and malignant ameloblastoma were made. An incisional biopsy was performed and sent for histopathological examination.

Hematoxylin and eosin-stained soft tissue section showed hypercellular areas of spindle shaped osteoblasts with malignant tumor osteoid (Fig. 7). Malignant osteoid showed variable areas of mineralization interspersed among the tumor cells (Fig. 8). The tumor cells exhibited marked pleomorphism, hyperchromatism, and increased mitotic activity (Fig. 9). Thus, the diagnosis of osteoblastic OS was given. Hemimandibulectomy of right mandible was planned but patient refused to undergo treatment.

\section{DISCUSSION}

According to World Health Organization (WHO) 2005, ${ }^{6}$ OS is defined as a primary malignant tumor of bone in which the neoplastic cells produce osteoid or bones. It accounts for approximately $20 \%$ of all sarcomas and are the most common primary bone tumors excluding hematopoietic neoplasms. ${ }^{7,8}$ Approximately 6 to $8 \%$ of OS occur in the jaws. ${ }^{2}$ Osteosarcoma are classified as primary and secondary (Table 1). ${ }^{9}$ Our present case belongs to conventional osteoblastic variant of OS. 

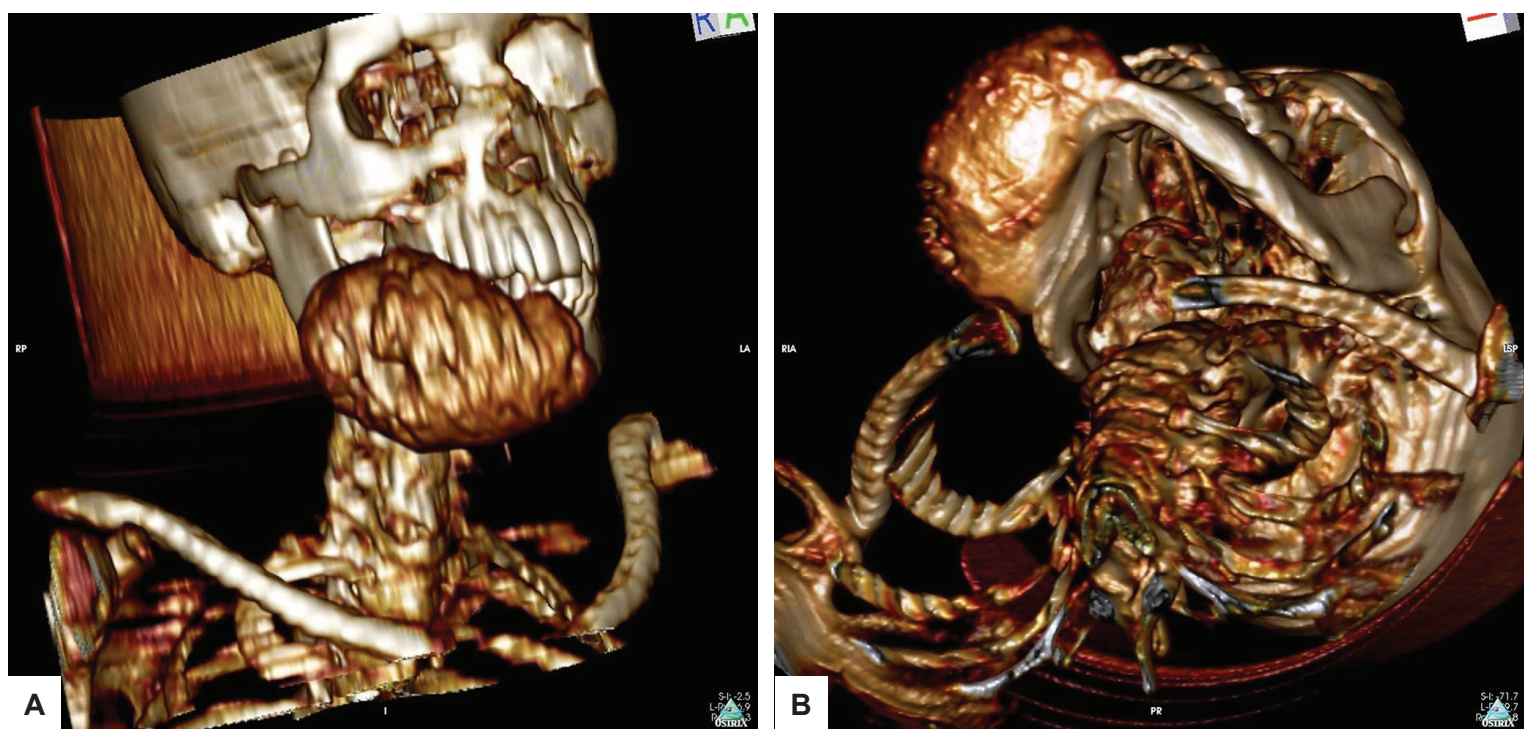

Figs $6 \mathrm{~A}$ and $\mathrm{B}$ : Three-dimensional reconstruction image confirming the extent of the lesion

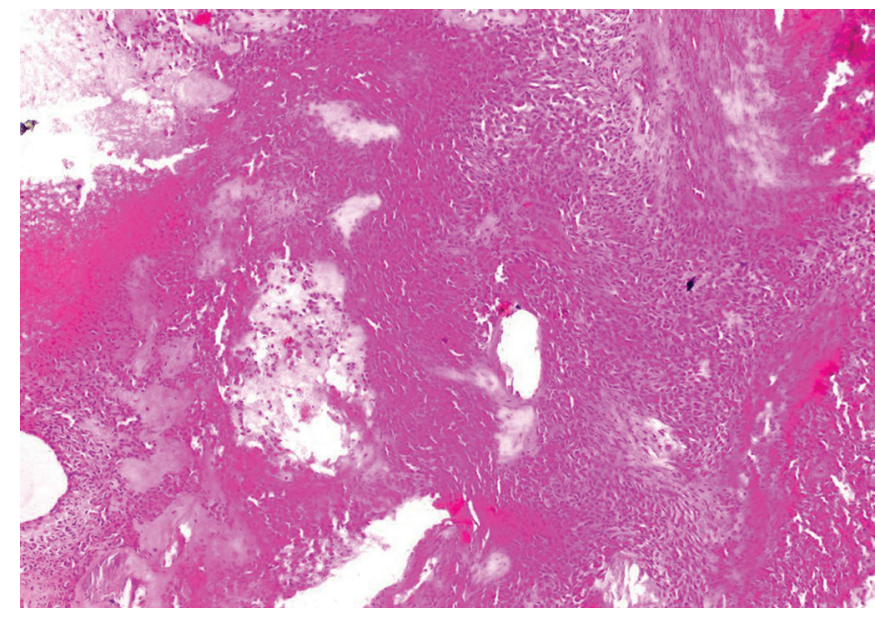

Fig. 7: Hematoxylin and eosin-stained (40x) stained soft tissue section shows hypercellular areas of spindle shaped osteoblasts

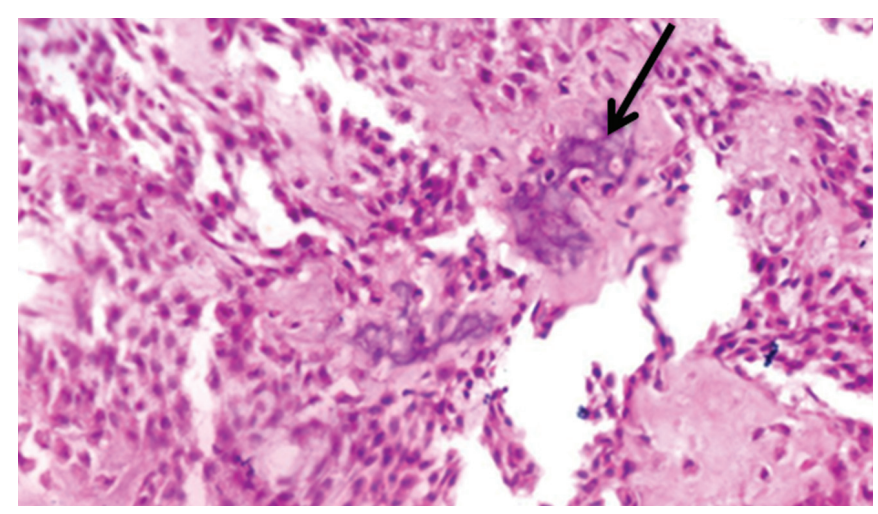

Fig. 9: Hematoxylin and eosin-stained (100x) stained soft tissue section shows osteoblasts exhibiting marked pleomorphism, hyperchromatism and increased mitotic activity with areas of tumor osteoid (arrow)

The exact cause of OS is unknown. However, a number of risk factors do exist. Osteosarcomas can arise de novo or in several preexisting bone abnormalities,

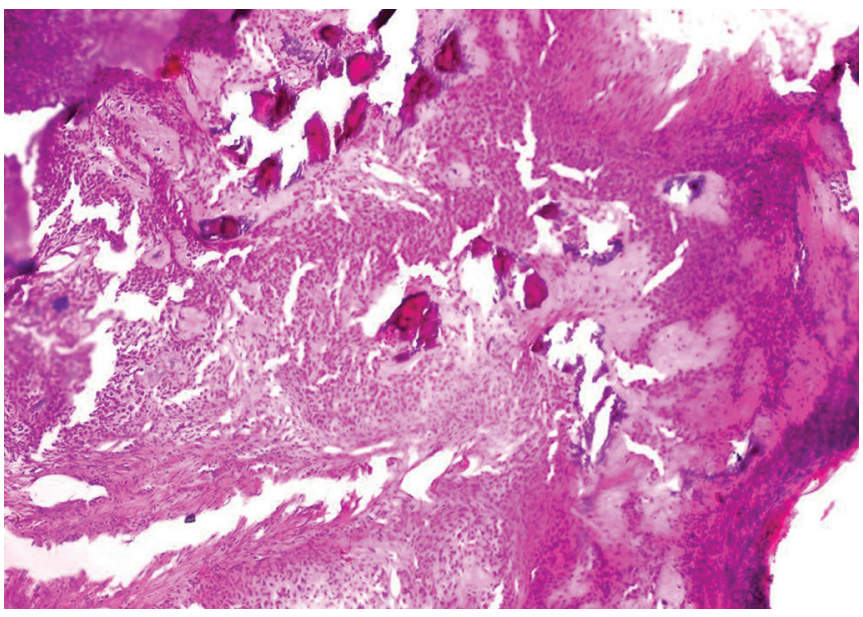

Fig. 8: Hematoxylin and eosin-stained (100x) stained soft tissue section shows presence of malignant osteoid showing variable mineralization interspersed among the tumor cells

such as Paget's disease, fibrous dysplasia, multiple osteochondromas, bone infarct, chronic osteomyelitis, and osteogenesis imperfect. ${ }^{7}$ Exposure to radiation is an environmental risk factor. ${ }^{10}$ Genetic mutations in tumor suppressor gene p53 and mutated retinoblastoma (RB) gene are the other etiological factors. In patients with RB, OS occurs 500 times more frequently than in the general population. ${ }^{11}$

The most common sites of OS include femur $(42 \%)$, tibia $(19 \%)$, humerus $(10 \%)$. In jaw OS, mandible is more commonly involved than maxilla, with the mandible accounting for 44 to $73 \%$ of cases and that of in maxilla is about 27 to $56 \%$ of cases. Mandibular tumors arise more frequently in body of mandible accounting 55 to $75 \%$ of cases followed in order of frequency by the angle, the ramus, and the symphysis. ${ }^{12}$ Jaw OS commonly presents itself in the $3 \mathrm{rd}$ and 4 th decades of life. ${ }^{8}$ A comparison of gnathic and extragnathic OS is given in (Table 2). ${ }^{4,8,13,14}$ Forteza 
Osteosarcoma of Mandible

Table 1: Classification of OS

\begin{tabular}{l}
\hline Primary OS \\
Conventional-intramedullary central high grade (most \\
common) further sub-typed as: \\
Osteoblastic $(50 \%)$ \\
Chondroblastic $(25 \%)$ \\
Fibroblastic (25\%) \\
Small cell \\
Telangiectatic \\
Low grade central \\
Surface OS: \\
Parosteal \\
Periosteal \\
High grade surface \\
Secondary OS can occur in Paget's disease and after radiation \\
exposure. \\
Unusal forms of OS given below are viewed as subtypes of \\
conventional OS because their behavior is similar. \\
Osteoblastic OS-sclerosing type \\
Osteosarcoma resembling OS \\
Chondromyxiod fibroma-like OS \\
Chondroblastoma-like OS \\
Clear cell OS \\
Malignant fibrous histocytoma-like OS \\
Giant cell OS \\
Epitheliod OS \\
\hline
\end{tabular}

et $\mathrm{l}^{15}$ did a study on 81 cases of OS and found that maxillary OS occurred in females with the ratio of $4: 1$, whereas mandibular lesions occurred only in males. The present case is rare, as it occurred in a 30-year-old female. The most common symptom of OS in the head and neck region is pain, swelling, mucosal ulceration, and loosening of teeth, which were also observed in our patient.

Radiographically, OS of the jaw has a purely lytic and destructive pattern (35-45\%), a sclerotic pattern (5-65\%), and mixed pattern of lysis and sclerosis $(22-50 \%) .{ }^{12}$ A sunburst pattern with radiating spicules of bone is considered a characteristic feature of OS of the jaw. It occurs only in 7 to $27 \%$ of cases. ${ }^{12}$ The present case showed the classic sunburst pattern.

Histopathologically, on the basis of the amount of osteoid cartilage or collagen fibers produced by tumor, they are classified as osteoblastic, chondroblastic, and fibroblastic. ${ }^{12}$ The osteoblastic variety consists of tumor osteoid surrounded by bizarrely arranged fibroblastlike cells. ${ }^{16}$ In chondroblastic OS, tumor cells lie in the lacunae and form lobules. The center of the lobule has bony trabeculae producing a feathery appearance, and toward the periphery, the tumor becomes hypercellular. Most of the times, an area of atypical chondroid tissue is also seen with large chondrocytes. Fibroblastic OS is the least common variant where the tumor cells are spindle-shaped. According to Garrington's study on 56 cases of jaw OS, $60 \%$ were osteoblastic, $34 \%$ were fibroblastic, and less than $10 \%$ were of chondroblastic
Table 2: Comparison of gnathic and extragnathic OS

\begin{tabular}{|c|c|c|}
\hline & Gnathic OS & Extragnathic OS \\
\hline Age & $\begin{array}{l}\text { Most often in 3rd and 4th } \\
\text { decade of life }\end{array}$ & $\begin{array}{l}\text { Bimodal age } \\
\text { of distribution } \\
\text { (10-20 } \\
\text { and } 50 \text { yrs) }\end{array}$ \\
\hline $\begin{array}{l}\text { Common } \\
\text { Site }\end{array}$ & Mandible & $\begin{array}{l}\text { Distal femur and } \\
\text { proximal tibial } \\
\text { metaphyses }\end{array}$ \\
\hline Metastasis & Less tendency to metastasize & $\begin{array}{l}\text { More metastatic } \\
\text { potential }\end{array}$ \\
\hline Prognosis & $\begin{array}{l}\text { - Less aggressive and } \\
\text { more favorable prognosis } \\
\text { compared to extragnathic OS. } \\
\text { - The worst prognosis is } \\
\text { associated with maxillary } \\
\text { antral OS and mandibular } \\
\text { symphysis OS have the best } \\
\text { prognosis. } \\
\text { - Chondroblastic variant } \\
\text { histopathological shows } \\
\text { worst prognosis. }\end{array}$ & $\begin{array}{l}\text { Aggressive and } \\
\text { poor prognosis }\end{array}$ \\
\hline $\begin{array}{l}5 \text { years } \\
\text { Survival rate }\end{array}$ & $50 \%$ & $30 \%$ \\
\hline
\end{tabular}

variant. ${ }^{10}$ The present case exhibits features of osteoblastic variant of OS.

Surgery and adjuvant chemotherapy radiotherapy may be required sometimes. The need of adjuvant therapy depends on the presence of micrometastases. In mandible, hemimandibulectomy is commonly preferred. A subtotal inferior maxillectomy for selected malignancies located on the alveolar ridge, palate and involving the antral floor have been described in literature. ${ }^{17}$ Overall, 5-year survival rate of $50 \%$ is reported for jaw OS. ${ }^{4}$ Patients with mandibular tumors generally fair better than those with maxillary tumors. Recurrence rate of OS of jaw is about 40 to $70 \%$ with a metastatic rate of 25 to $50 \%{ }^{7}$ Osteosarcomas are more likely to metastasize to lung and to brain than to regional lymph nodes. ${ }^{7}$ In the present case, the patient refused to undergo treatment and was lost to follow-up.

\section{CONCLUSION}

Osteosarcoma is a very aggressive neoplasm of OS origin with a potent risk of metastasis. Early diagnosis of this lesion may have a bearing on better prognosis and survival rate. Hence, a triple diagnostic approach, i.e., clinical, radiological, and histopathology, is essential for an accurate, and timely diagnosis.

\section{REFERENCES}

1. Bennett JH, Thomas G, Evans AW, Speight PM. Osteosarcoma of the jaws: a 30-year retrospective review. Oral Surg Oral Med Oral Pathol Oral Radiol Endod 2000;90:323-32.

2. Balwani SR, Tupaki JV, Barpande SR. Parosteal osteosarcoma of the mandible. J Oral Maxillofac Pathol 2006;10:10-14. 
3. Ong ST, Shim CK, Ng Kok-Han, Siar CH. Osteosarcoma presenting as an aggressive nodular mass in the region of the mandible. J Oral Sci 2004 Mar;46(1):55-59.

4. Marx ER, Stern D. Oral and Maxillofacial Pathology: a Rationale for Diagnosis and Treatment, volume 2. 2nd ed. Illinois: Quintessence Publishing Company; 2012. p. 859.

5. Bielack SS, Kempf-Bielack B, Delling G, Exner GU, Flege S, Helmke K, Kotz R, Salzer-Kuntschik M, Werner M, Winkelmann W, et al. Prognostic factors in high-grade osteosarcoma of the extremities or trunk: an analysis of 1,702 patients treated on neoadjuvant cooperative osteosarcoma study group protocols. J Clin Oncol 2002;20(3); 776-790.

6. Barnes L, Eveson JW, Reichart P, Sidransky D. World Health Organization classification of tumours, pathology and genetics of tumors of head and neck tumours. Lyon: IARC Press; 2005. p. 52.

7. Jordan RS. Oral Pathology: Clinical Pathologic Correlation. 6th ed. Chapter 14. Malignancies of jaw. Missouri: Elsevier. pp. 328-335.

8. Neville BW, Damm DD, Allen CM, Bouquot JE. Bone pathology. In: Neville BW, Damm DD, Allen CM, Bouquot JE, editors. Oral and maxilofacial pathology. Philadelphia: Saunders; 2002. pp. 574-577.
9. Kundu ZS. Classification, imaging, biopsy and staging of osteosarcoma. Indian J Orthop 2014 May;48(3):238-246.

10. Rajendran R. Benign and Malignant Tumors of the Oral Cavity. In: Rajendran R, Sivapathasundaram B, editors. Shafer's Textbook of Oral Pathology. 6th ed. Amsterdam: Elsevier; 2009. pp. 169-173.

11. Picci Piero. Osteosarcoma (Osteogenic sarcoma). Orphanet J Rare Dis 2007;2:6.

12. Gnepp DR. Diagnostic surgical pathology of the Head and Neck. 2nd ed. Philadelphia: Elsevier; 2009. p. 667.

13. Garrington GE, Scofield HH, Cornyn J, Hooker SP. Osteosarcoma of the jaws. Analysis of 56 cases. Cancer 1967 Mar;20(3):377-391.

14. Paparella ML,OlviLG, BrandizziD, Keszler A,Santini-Araujo E, Cabrini RL. Osteosarcoma of the jaw: an analysis of a series of 74 cases. Histopathology 2013 Oct;63(4):551-557.

15. Forteza G, Colmenero B, Lopez-Barea F. Osteogenic sarcoma of maxilla and mandible. Oral Surg Oral Med Oral Pathol 1986 Aug;62(2):179-184.

16. Chaudhary M, Chaudhary SD. Osteosarcoma of jaws. J Oral Maxillofac Pathol 2012 May;16(2):233-238.

17. Pogrel MA. Inferior hemi-maxillectomy for treatment of palatal tumors. J Oral Maxillofac Surg 1988 Jan;46(1): 85-87. 